TAPROBANICA, ISSN 1800-427X. May, 2021. Vol. 10, No. 01: pp. 39-46, pl. 9.

(C) Research Center for Climate Change and Department of Biology, Faculty of Mathematics \& Natural Sciences, University of Indonesia, Depok 16424, INDONESIA.

http://www.taprobanica.org

https://doi.org/10.47605/tapro.v10i1.246

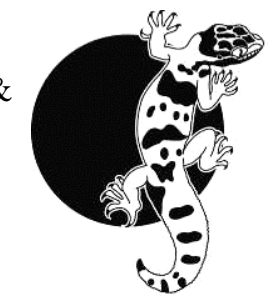

\title{
FIRST RECORD OF Pareas vindumi VOGEL, 2015 (REPTILIA: PAREIDAE) FROM CHINA WITH A REVISION TO MORPHOLOGY
}

\author{
Jian-Huan Yang ${ }^{1,3}$, Ho Yuen Yeung ${ }^{1}$, Xiang-Yuan Huang ${ }^{2} \&$ Shen-Pin Yang ${ }^{2}$ \\ ${ }^{1}$ Kadoorie Conservation China, Kadoorie Farm \& Botanic Garden, Lam Kam Road, Tai Po, Hong Kong, China \\ ${ }^{2}$ Yunnan Gaoligongshan National Nature Reserve (Tengchong Bureau), 157 Laifeng Ave., Tengchong 679100, \\ Yunnan Province, China \\ ${ }^{3}$ Corresponding author. E-mail: jhyang@kfbg.org
}

\begin{abstract}
We report the first record of the poorly known slug-eating snake, Pareas vindumi from China: a female specimen collected from Dazhuba ranger station, Gaoligongshan National Nature Reserve, Tengchong city, Yunnan Province. The newly collected specimen represents only the second known specimen of the species and provides the first and valuable data on its morphological variation. Based on the new specimen, we revise the diagnostic characteristics of the species and provide additional data on its natural history and conservation status.
\end{abstract}

Key words: molecular taxonomy, morphological variation, new record, Pareinae, slug-eating snake

\section{Introduction}

Snakes of the genus Pareas Wagler are small arboreal nocturnal snakes, which are characterized by their distinctly blunt snout and specialized slug and terrestrial snail-eating behavior (You et al. 2015, Wang et al. 2020). Pareas snakes are widely distributed in subtropical and tropical Asia, extending from the northeast India in the west, through southern China to the Ryukyu Archipelago of Japan in the east, and through Myanmar and mainland Southeast Asia to the island of Java in Indonesia in the south (You et al. 2015, Wang et al. 2020). With the recent resurrections of $P$. andersonii Boulenger, 1888 and $P$. modestus Theobald, 1868 , and descriptions of three new species from Indochina, southern China and Myanmar, a total of 22 species are now recognized in the genus (Uetz et al. 2021, Vogel et al. 2020, 2021; Ding et al. 2020; Liu et al. 2021).

During herpetological surveys conducted in the Tengchong Section of Gaoligongshan National Nature Reserve (TC-GLGS), Yunnan Province, China in 2014-2018, we collected a peculiar specimen of the genus Pareas. This slug-eating snake appeared to be similar to $P$. vindumi Vogel, 2015, which is a poorly known species recently described from an adjacent part of northern Myanmar based on a single female specimen (Vogel 2015). However, our specimen showed some differences from the original description of $P$. vindumi in a number of key morphological characters and was therefore tentatively listed as an unknown species in our 
recent herpetofauna checklist of TC-GLGS (Yang et al. 2019).

With the availability of genetic sequences of $P$. vindumi recently published in Vogel et al. (2020), we re-assessed the taxonomic status of the unknown Pareas using an integrative approach incorporating molecular and morphological methods. The molecular analyses revealed that the unknown Pareas is conspecific with $P$. vindumi with extremely low genetic divergence. Furthermore, considering the close distance between two collection sites (ca. $34 \mathrm{~km}$ in straight line distance between the type locality of $P$. vindumi and our collection site, see Fig. 1), we therefore argue that our specimen can be allocated to $P$. vindumi, while the notable morphological differences observed likely represent intraspecific variations which are described in detail below.

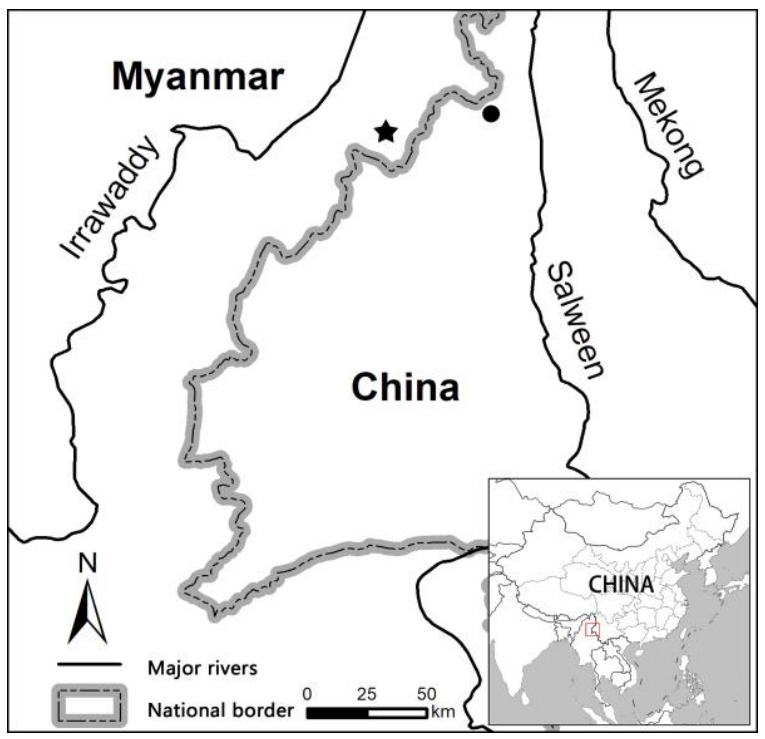

Figure 1. Current known localities of Pareas vindumi. the type locality (Lukpwi Village, Chipwi, Kachin, Myanmar) is shown with a star, the new record (this study) with a circle.

\section{Materials and methods}

Sampling. One adult female specimen was collected from Dazhuba ranger station, Gaoligongshan National Nature Reserve, Tengchong City, Yunnan Province, China, $25^{\circ} 45.762^{\prime} \mathrm{N}, 98^{\circ} 39.434 ' \mathrm{E}, 2,140 \mathrm{~m}$ a.s.l., by J.H. Yang, on 20 May 2015. The specimen was preserved in $80 \%$ ethanol and deposited at the Herpetological collection of Kadoorie Farm and Botanic Garden (KFBG), Hong Kong.

Morphology. Measurements were taken by J.-H.Yang with a digital caliper (Mitutoyo CD-6 CS Digital Caliper, Japan) to the nearest 0.1 $\mathrm{mm}$ : snout-vent length from the tip of the snout to the anterior margin of the opening of the cloaca; tail length from the posterior margin of the opening of the cloaca to the tip of tail; head length from the tip of the snout to the posterior margin of the mandible; head width at widest part of head; head height at highest part of head. Ventral scales counts followed Dowling (1951); dorsal scale rows were counted at anterior neck (at the level of the $15^{\text {th }}$ ventral scale from the head), mid-body (halfway between rear of head and opening of cloaca), and anterior to cloaca (at the level of the $15^{\text {th }}$ ventral scale anterior to the opening of the cloaca). Number of maxillary teeth was determined by dissection. Sex was determined by the presence of eggs in the body cavity.

DNA extraction and sequencing. Genomic DNA was extracted from the muscle tissue using a TIANamp Genomic DNA Kit (Tiangen Biotech). We amplified fragments of cytochrome $b$ (cyt $b$ ) gene using the primer pairs L14910/H16064 (Lawson et al. 2005). PCR amplifications were performed in a reaction volume of $25 \mu \mathrm{l}$ containing $100 \mathrm{ng}$ of template DNA, $0.3 \mathrm{mM}$ of each PCR primer, and $10 \mu \mathrm{l}$ Premix EX TaqTM (Takara). The PCR conditions were an initial denaturing step at $95^{\circ} \mathrm{C}$ for $4 \mathrm{~min}$, followed by 35 cycles of denaturing at $94^{\circ} \mathrm{C}$ for $30 \mathrm{~s}$, annealing at $52^{\circ} \mathrm{C}$ for 30s, an extension step at $72^{\circ} \mathrm{C}$ for $1 \mathrm{~min}$; and a final extension of $72^{\circ} \mathrm{C}$ for $7 \mathrm{~min}$ (Yang \& Zheng 2018). PCR products were purified with spin columns. The purified products were sequenced with respective forward and reverse primers using BigDye Terminator Cycle Sequencing Kit (Thermo Fisher Scientific Inc., Waltham, MA) according to the guidelines of the manufacturer. The PCR products were sequenced on an ABI Prism 3730 automated DNA sequencer at the ShangHai Majorbio Biopharm Technology Co., Ltd.

Phylogenetic analyses. In addition to our unknown specimen of Pareas, we included sequences of all species of Pareas for which cyt $b$ sequences were available from GenBank for genetic analysis, as well as two species of Asthenodipsas and Aplopeltura boa (Boie, 1828). Dinodon rufozonatum (Cantor, 1842) and Gloydius blomhoffi (Boie, 1826) were used as outgroups (Table 1).

The sequences were aligned by Muscle 3.6 (Edgar 2004) under default settings, checked by eye, and adjusted if necessary. Phylogenetic trees were constructed based on a concatenated dataset using maximum likelihood (ML) and 
Bayesian inference (BI). Maximum likelihood analysis was conducted in RaxmlGUI 1.3 (Silvestro \& Michalak 2012). Confidence intervals were determined with 1000 bootstrap replicates utilizing the rapid bootstrap option under the HKY+G+I substitution model. Bayesian analyses were performed in MrBayes 3.2.7 (Ronquist et al. 2012) under the GTR+G model as suggested by the Akaike Information Criterion implemented in jModelTest 2.1.2 (Darriba et al. 2012). We employed two separate MCMC runs, each with four Metropolis-coupled chains. The analyses were run for 2.5 million generations, with parameters and topology sampling every 1000 generations. The stationary phase was detected using Tracer 1.6 (Rambaut et al. 2014). The first 1000 trees were discarded as burn-in, and posterior probabilities were determined from the remaining trees. We also calculated the uncorrected pairwise genetic distances using MEGA X (Kumar et al. 2018).

We assessed the confidence in tree topology by the posterior probability (BI PP) for the Bayesian Inference (Huelsenbeck and Ronquist 2001), and by bootstrap replications (ML BS) for the Maximum Likelihood analysis. We a priori regarded the tree nodes with ML BS values of $75 \%$ or higher and BI PP values over 0.95 as sufficiently resolved; ML BS values between $75 \%$ and $50 \%$ and BI PP values between 0.95 and 0.90 were regarded as tendencies, and lower values were regarded as a lack of node support (Huelsenbeck and Hillis 1993).

\section{Results}

Mitochondrial genealogy. The fragment of the cyt $b$ gene contains $1086 \mathrm{bp}$ characters. Both the ML tree and BI analyses strongly supported that the unknown Pareas from TC-GLGS is grouped with $P$. vindumi with high levels of node support (1.0/100 for BI PP and ML BS values, respectively), and then together formed a genetically distinct lineage and was clustered into the same clade with $P$. hamptoni (Boulenger, 1905), P. niger (Pope, 1928), $P$. formosensis (Van Denburgh, 1909), P. geminatus Ding et al., 2020, P. xuelinensis Liu \& Rao, 2021, P. kaduri (Bhosale et al., 2020) and P. nigriceps Guo \& Deng, 2009 (Fig. 2).

Table 1. Sequences and voucher specimens of Pareas and outgroup taxa used in the phylogenetic analysis in this study; Mt., mountain; Is., island; Hw., highway.

\begin{tabular}{|c|c|c|c|c|}
\hline species & voucher no. & locality & $\begin{array}{l}\text { Genbank } \\
\text { no. }\end{array}$ & Source \\
\hline Pareas andersonii & CAS 235359 & Myanmar, Chin, Mt. Natmataung & MT968772 & Vogel et al. 2020 \\
\hline Pareas atayal & NMNS 05594 & China, Taiwan, N. Cross Is. Hw. & KJ642122 & You et al. 2015 \\
\hline Pareas boulengeri & GP 2923 & China, Guizhou, Jiangkou & MK135090 & Wang et al. 2020 \\
\hline Pareas carinatus & LSUHC10604 & Malaysia, Kedah, Sungai Sedim & КС916748 & Loredo et al. 2013 \\
\hline Pareas chinensis & GP 2196 & China, Sichuan, Hongya & MK135089 & Wang et al. 2020 \\
\hline Pareas formosensis & NMNS 05632 & China, Taiwan, N. Cross Is. & KJ642130 & You et al. 2015 \\
\hline Pareas geminatus & CIB 118021 & China, Yunnan, Jiangcheng & MW287068 & Ding et al. 2020 \\
\hline Pareas hamptoni & CAS 221489 & Myanmar, Kachin, Naung Mon & МT968777 & Vogel et al. 2020 \\
\hline Pareas iwasakii & I03-ISG1 & Japan, S. Ryukyu, Ishigaki Is. & KJ642158 & You et al. 2015 \\
\hline Pareas kaduri & BNHS 3574 & India, Arunachal, Lohit & MT188734 & Bhosale et al. 2020 \\
\hline Pareas komaii & HC 000669 & China, Taiwan, Taitung, Lijia & JF827687 & Guo et al. 2011 \\
\hline Pareas macularius & CAS 206620 & Myanmar, Bago Division & AF471082 & Guo et al. 2011 \\
\hline Pareas margaritophorus & N/A & China, Hong Kong & KJ642197 & You et al. 2015 \\
\hline Pareas menglaensis & YBU 14124 & China, Yunnan, Mengla & MK135114 & Wang et al. 2020 \\
\hline Pareas modestus & MZMU 1293 & India, Mizoram, Aizawl, Tanhril & MT968773 & Vogel 2020 \\
\hline Pareas monticola & GP 2027 & China, Tibet, Motuo & MK135107 & Wang et al. 2020 \\
\hline Pareas niger & KIZ 059339 & China, Yunnan, Kunming & MW436706 & Liu \& Rao 2020 \\
\hline Pareas nigriceps & SYSr001222 & China, Yunnan, Tengchong & MK201455 & Li et al. 2020 \\
\hline Pareas stanleyi & HM 2007-S001 & China, Guangxi, Guilin & JN230704 & Guo et al. 2011 \\
\hline Pareas victorianus & CAS 235254 & Myanmar, Chin Mt. Natmataung & MW438300 & Vogel et al. 2021 \\
\hline Pareas vindumi & CAS 248147 & Myanmar, Kachin, Lukpwi & МТ968776 & Vogel et al. 2020 \\
\hline Pareas vindumi & KFBG 14360 & China, Yunnan, Tengchong & MZ169542 & This study \\
\hline Pareas xuelinensis & KIZ XL1 & China, Yunnan, Lancang & MW436709 & Liu \& Rao 2021 \\
\hline Aplopeltura boa & KIZ 011963 & West Malaysia & JF827673 & Guo et al. 2011 \\
\hline Asthenodipsas lasgalenensis & LSUHC8869 & Malaysia, Perak, Bukit Larut & KC916758 & Loredo et al. 2013 \\
\hline Asthenodipsas malaccanus & FMNH 273617 & Malaysia, Sarawak, Bintulu & KX660469 & Figueroa et al. 2016 \\
\hline Dinodon rufozonatum & CIB 098274 & unknown & JF827672 & Guo et al. 2011 \\
\hline Gloydius blomhoffi & CIB 088188 & unknown & JF827674 & Guo et al. 2011 \\
\hline
\end{tabular}


Furthermore, the uncorrected pairwise divergence between the unknown Pareas from TC-GLGS and holotype of $P$. vindumi is very low, $p=1.1 \%$ (Table 2), indicating that these two specimens are conspecific (Shen et al. 2013). Therefore, we confirm that our specimen can be safely allocated to $P$. vindumi.

Description of Chinese specimen. Specimen KFBG 14360; adult female; snoutvent length $505.1 \mathrm{~mm}$, tail length $116.4 \mathrm{~mm}$; head length $20.1 \mathrm{~mm}$; head width $11.3 \mathrm{~mm}$; head height $8.5 \mathrm{~mm}$; snout length $5.1 \mathrm{~mm}$; eye-nostril distance $2.5 \mathrm{~mm}$. Head moderate in size and oval in dorsal view, distinct from neck; head near twice wider than neck width; snout distinctly blunt, projecting beyond the lower jaw in lateral view. Eye large, $3.1 \mathrm{~mm}$ in diameter, rounded in shape and distinctly protruding; pupil slightly vertical. Body laterally compressed, slightly oval-shaped in cross-section in the middle of length.

Rostral single, large, slightly higher than wide $(4.1 \mathrm{~mm}$ vs $3.8 \mathrm{~mm})$, slightly visible in dorsal view, and with a distinct concave furrow on the ventral side; nasal one, undivided, pierced by a distinct oval-shaped nostril in the center; loreal 1/1, tiny and triangular, surrounded by nasal, preocular, prefrontal and internasal; preocular $1 / 1$, rhombus-shaped, anteriorly in contact with nasal and loreal, dorsally in contact with prefrontal, posteriorly touching eye, ventrally in contact with $2^{\text {nd }}$ to $3^{\text {rd }}$ supralabials $\left(2^{\text {nd }}\right.$ and $3^{\text {rd }}$ on the left side, only $2^{\text {nd }}$ on the right side) and subocular; subocular $1 / 1$, fused with postocular, elongated and semi-crescent in shape, in contact with $3^{\text {rd }}$ to $5^{\text {th }}$ on the left side, and $2^{\text {nd }}$ to $5^{\text {th }}$ on the right side; supralabials $7 / 7$, not in contact with eye, the last one elongated (about 3.8 times wider than high); primary temporals $2 / 2$, lower one about the same side as the upper one; secondary temporals $3 / 3$; mental triangular, about two times broader than long (3.3 $\mathrm{mm}$ in width, $1.6 \mathrm{~mm}$ in length), followed by a diamond-shaped postmental $(3.1 \mathrm{~mm}$ in width; $1.9 \mathrm{~mm}$ in length); infralabials $7 / 7$, the first one separated from each other by the mental and postmental, the $6^{\text {th }}$ one widened and inserting a bit between $2^{\text {nd }}$ and $3^{\text {rd }}$ pairs of chin shields, the $7^{\text {th }}$ one elongated; three pairs of chin shields interlaced, no mental groove under chin and throat; anterior chin shields longer than broad $(5.0 \mathrm{~mm}$ in length, $3.0 \mathrm{~mm}$ in width), posteriorly followed by two pairs of chin shields broader than long; internasals two, wider than long (2.9 $\mathrm{mm}$ in width, $1.8 \mathrm{~mm}$ in length), anteriorly in contact with rostral, laterally in contact with nasal and loreal, posteriorly in contact with prefrontal, not touching preocular; prefrontals two, wider than long $(3.4 \mathrm{~mm}$ in width, $2.1 \mathrm{~mm}$ in length), laterally in contact with loreal, preocular and eye, posteriorly in contact with supraocular and frontal; internasal suture $(1.4 \mathrm{~mm})$ shorter than prefrontal suture $(1.7 \mathrm{~mm})$; supraocular large and elongated, in crescent-shaped, about three times longer than wide ( $4.3 \mathrm{~mm}$ in length, $1.4 \mathrm{~mm}$ in width) in dorsal view; frontal large, sub-hexagonal, with rounded anterior and acute posterior angles, about 1.17 times longer than wide $(5.6 \mathrm{~mm}$ in length, $4.8 \mathrm{~mm}$ in width); frontal 1.33 times longer than the distance from it to the tip of snout $(4.2 \mathrm{~mm})$; parietals large, nearly twice as large as frontal, about 1.84 times longer than wide ( $8.1 \mathrm{~mm}$ in length, $4.4 \mathrm{~mm}$ in width), median parietal suture $(5.5 \mathrm{~mm})$ about as long as frontal, anteriorly in contact with frontal and supraocular, laterally and posteriorly bordered by seven scales on the left side and by five scales on the right side (including the upper temporals); enlarged nuchal scales present.

Dorsal scales in 15 rows throughout the body, weakly keeled on median five rows on neck, median 11 rows at mid-body and at posterior of body (keels on inner seven rows distinct than outer ones); vertebral scales not enlarged; all dorsal scales without apical pits; ventrals 175 , the last one not divided; preventral scale absent; subcaudals divided, 60 pairs; terminal caudal scale forming acuminated tail cap. Five maxillary teeth on both sides.

Coloration in life. Main background coloration of dorsum reddish brown (Fig. 3). The top of head pigmented with dull dark brown. Two short, dark brown longitudinal stripes present from the back of head to the nape, followed by approximately 63 indistinct narrow dark brown cross-bars throughout the body and tail. Lateral side of head scattered with irregular, tiny dark brown speckles. Ventral sides of head, body and tail yellowish white, all mottled with irregular, tiny dark brown speckles. Iris reddish brown, which is similar to the background coloration of dorsum.

Variation. The dorsal scales of the female holotype $P$. vindumi were noted as smooth in its original description (Vogel 2015). However, the holotype actually has very weak keels on dorsal scales which were overlooked by the author (G. Vogel 2020, pers. comm. on 3 Oct). Therefore, we confirm that both the holotype of $P$. vindumi 
and KFBG 14360 have weakly keeled dorsal scales. Specimen KFBG 14360 greatly resembles the holotype of $P$. vindumi in overall coloration and scalation, but still has some notable morphological variations: the presence of a tiny scale between nasal and loreal (see Fig. 4; vs absent in the holotype); seven supralabials ( $v s$ six in the holotype); seven infralabials ( $v s$ six in the holotype); the absence of a pre-subocular scale ( $v s$ present in the holotype); the presence of a postmental scale (see Fig. 4; vs absent in the holotype); first infralabial separated from each other behind the mental shield (vs touching each other in the holotype); three pairs of chin shields ( $v s$ two pairs in the holotype, see Figure 2 in Vogel 2015).

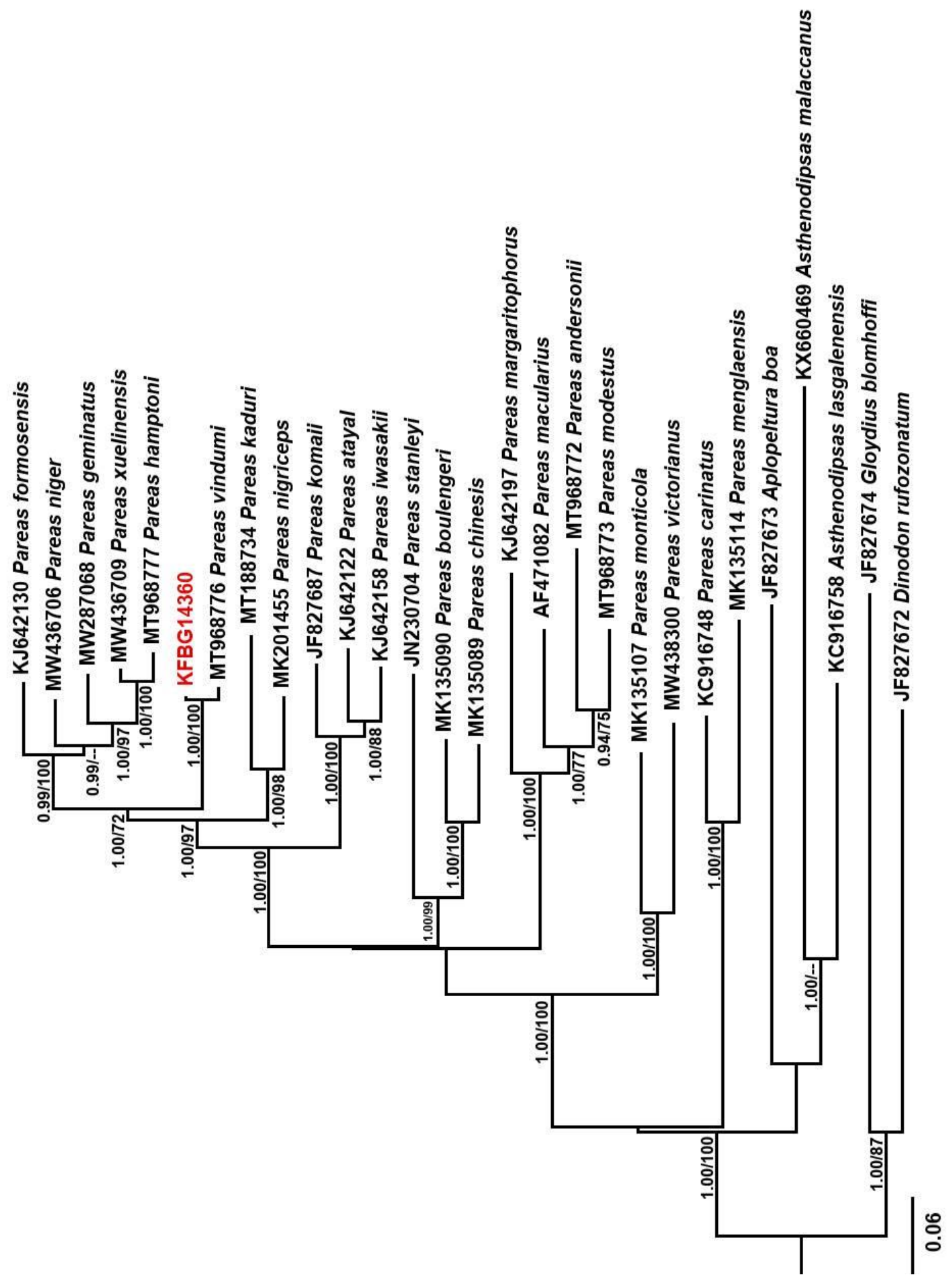

Figure 2. Maximum likelihood (ML) tree derived from partial sequences of the combined fragments of cyt $b$ genes. Numbers at nodes correspond to Bayesian posterior probabilities (BI PP; $>70 \%$ retained) and to Maximum Likelihood bootstrap values (ML BS; > 70\% retained). 


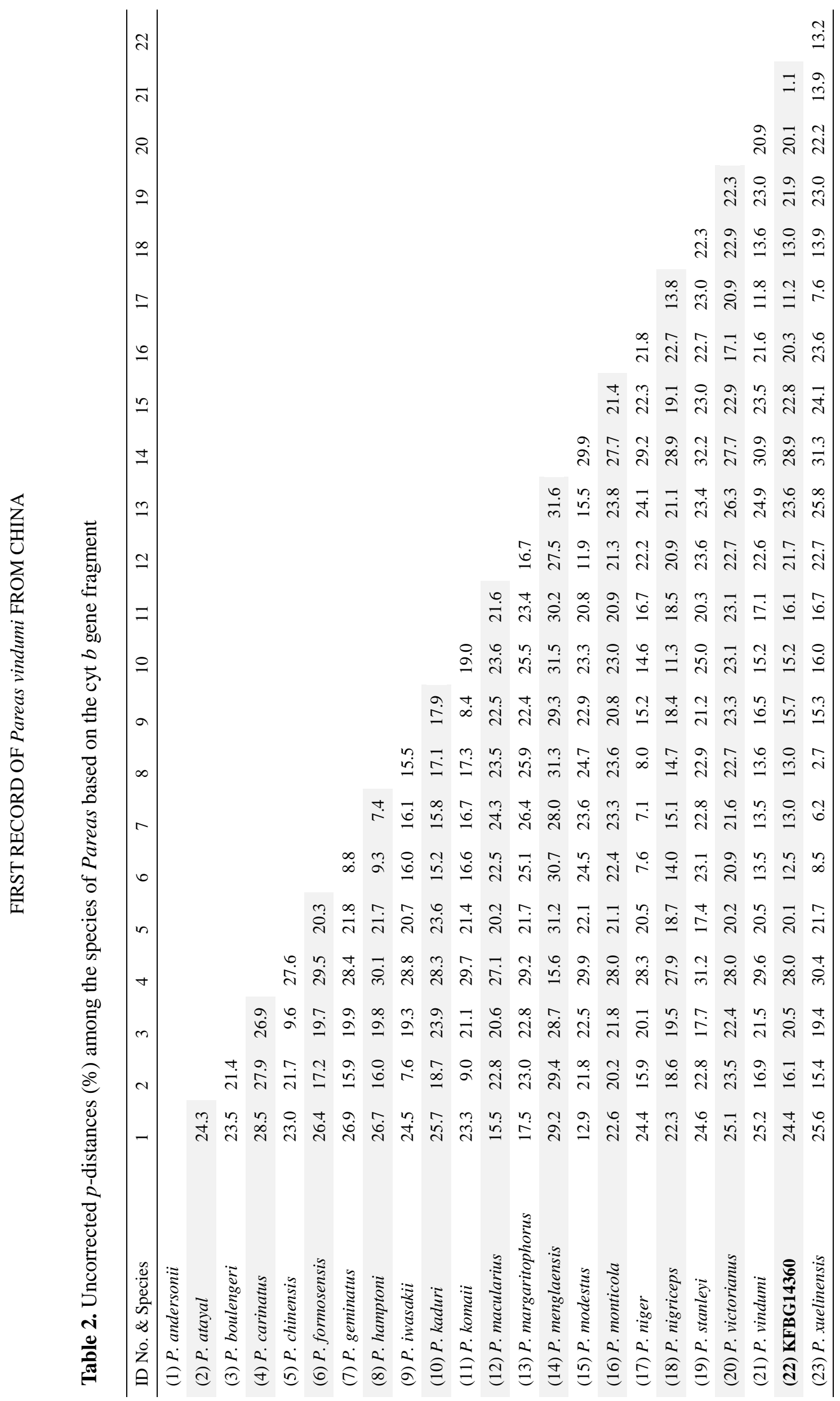




\section{Plate 09}

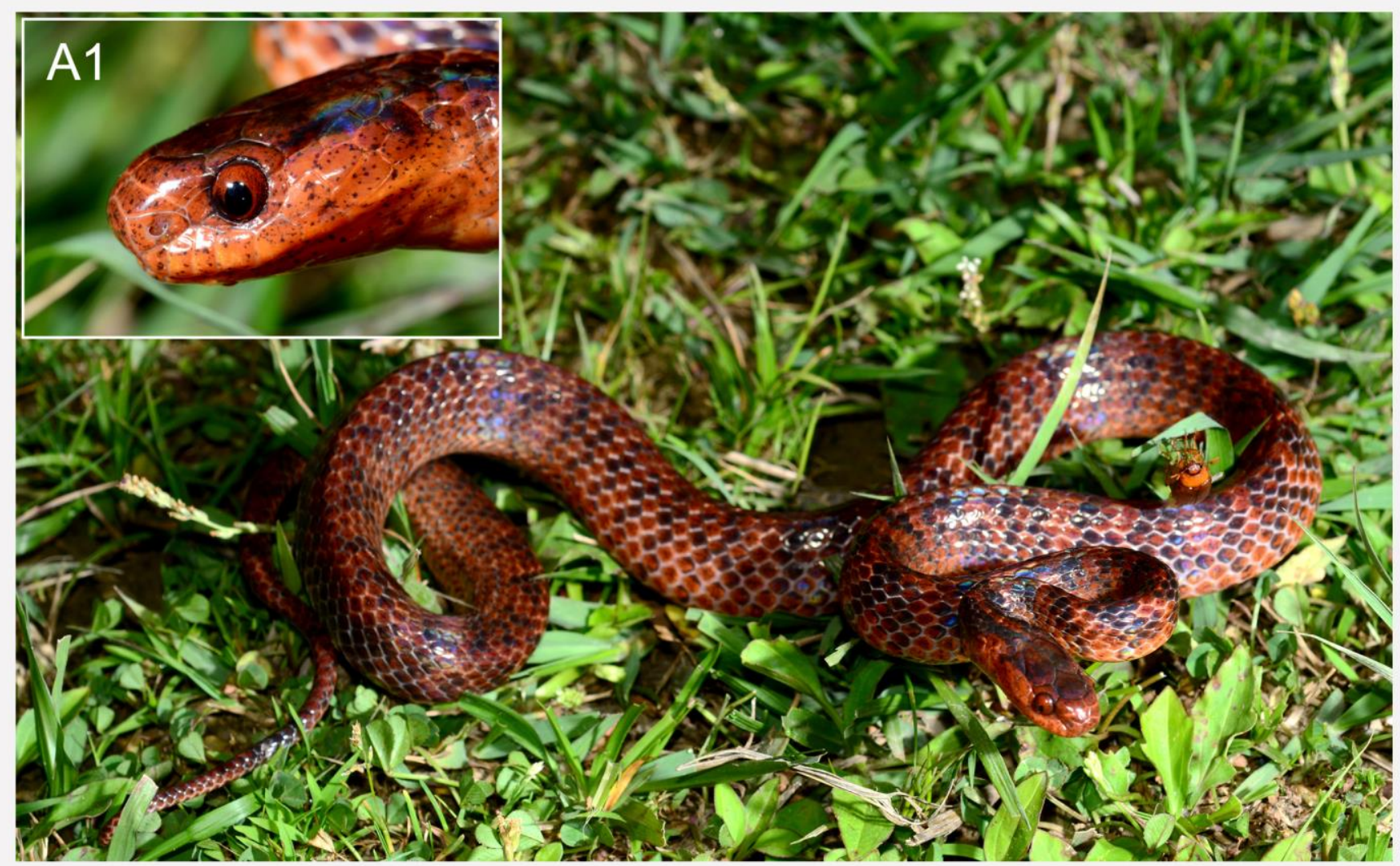

Figure 3. Pareas vindumi (KFBG 14360) from Dazhuba ranger station, Gaoligongshan National Nature Reserve, Tengchong, Yunan, China showing the dorsolateral view of full body; (A1) lateral head (note the iris colour)

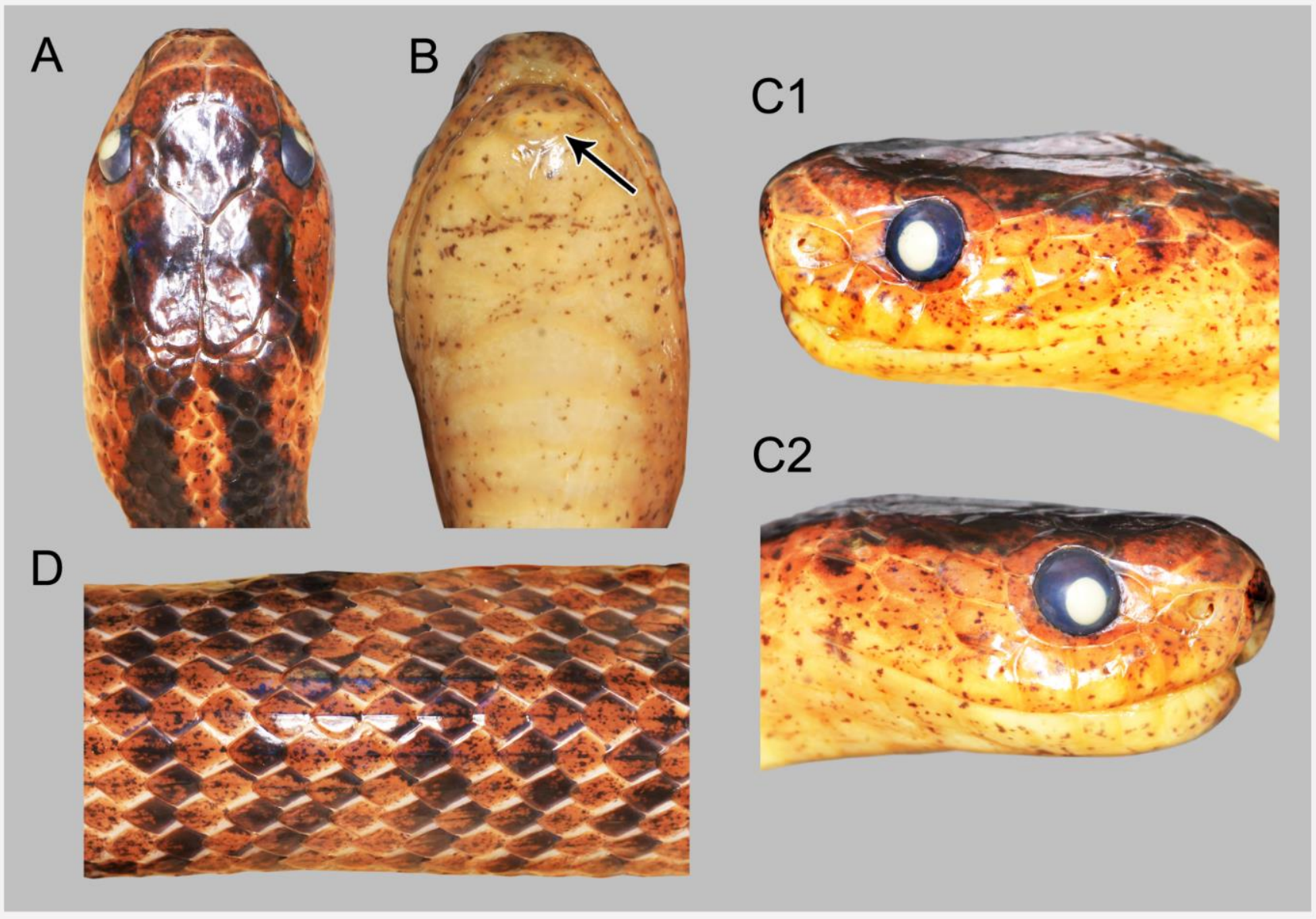

Figure 4. Pareas vindumi (KFBG 14360): head in (A) dorsal, (B) ventral, and (C) lateral view; (D) mid body in dorsal view (note non-enlarged vertebral scales and keels on scales); arrow points to the postmental scale. 
Revision of diagnostic characters. According to the morphological variations observed in the additional Chinese specimen of Pareas vindumi, we modified the diagnosis of this species below: P. vindumi differs from other species in the genus by having a comparatively large body size (total length $621.5-657 \mathrm{~mm}$ in two known adult females); dorsal scales weakly keeled in 11 rows; preocular absent; loreal broadly touching with eye; postocular fused with subocular, 173-175 ventrals in females; 60-61 pairs of subcauduals in females; supralabials 67; infralabials 6-7; primary temporals two; narrow black postorbital stripe absent. Iris reddish brown in life.

Natural history. The female KFBG 14360 was found on the ground at the forest edge during a night survey at 20:00 h on 20 May 2015. Data on other sympatric herpetofauna in TC-GLGS can be referred to Yang et al. (2019). The gravid KFBG 14360 contained eight eggs in its abdomen.

\section{Discussion}

It is worth mentioning that the absence of a postmental scale (defined as "anterior inframaxillary" in Grossmann \& Tillack 2003) is one of the key diagnostic characters that separates Pareas from the other two Pareinae genera Aplopeltura and Asthenodipsas (Rao \& Yang 1992, Grossmann \& Tillack 2003). Therefore, the presence of a postmental scale in KFBG 14360 represents the first documented Pareas species having this character (see Fig. 4E). Furthermore, the difference in number of chin shield pairs between holotype and KFBG 14360 of $P$. vindumi (two vs three pairs) is a rare case of morphological variation in the genus Pareas since until now this genus was characterized by having three pairs of chin shields (Rao \& Yang 1992, Grossmann \& Tillack 2003). More specimens are needed to better understand the morphological variation within $P$. vindumi.

Unlike most congeners in southern China and Southeast Asia, P. vindumi seems to be more elusive and relatively uncommon, as it is so far only known from two specimens. Within TCGLGS, we have conducted 57 field days between 2014 and 2018 covering different seasons, but only a single specimen of the species has been found, making it one of the most rarely seen snake species during our four years of surveys (Yang et al. 2019). In view of the uncertainty of its extent of occurrence, elusive habits, and little information on its ecology and threats, we propose $P$. vindumi to be listed as Data Deficient, following the IUCN Red List Categories and Criteria (IUCN 2012).

\section{Acknowledgements}

This study was supported by Kadoorie Farm and Botanic Garden, Hong Kong. We thank forestry rangers of TC-GLGS and colleagues of KFBG who helped in the fieldwork. Gernot Vogel (Germany), Nick Poyarkov (Lomonosov Moscow State University, Moscow), and Thasun Amarasinghe (University of Indonesia, Depok) are thanked for reviewing the manuscript.

\section{Literature cited}

Bhosale, H., P. Phansalkar, M. Sawant, G. Gowande et al. (2020). A new spe $\neg$ cies of snail-eating snakes of the genus Pareas Wagler, 1830 (Reptilia: Serpentes) from eastern Himalayas, India. European Journal of Taxonomy, 729 (1): 54-73.

Darriba, D.G., L. Taboada, R. Doallo and D. Posada (2012). jModelTest 2: more models, new heuristics and parallel computing. Nature Methods, 9 (8): 772.

Ding, L., Z. Chen, C. Suwannapoom, T.V. Nguyen, N.A. Poyarkov, and G. Vogel (2020). A new species of the Pareas hamptoni complex (Squamata, Serpentes, Pareidae) from the Golden Triangle. Taprobanica, 9 (2): 174193.

Dowling, H.G. (1951). A proposed standard system of counting ventrals in snakes. British Journal of Herpetology, 1: 97-99.

Edgar, R.C. (2004) MUSCLE: multiple sequence alignment with high accuracy and high throughput. Nucleic Acids Research, 32 (5): 1792-1797.

Grossmann, W. and F. Tillack (2003) On the taxonomic status of Asthenodipsas tropidonotus (Van Lidth de Jeude, 1923) and Pareas vertebralis (Boulenger, 1900) (Serpentes: Colubridae: Pareatinae). Russian Journal of Herpetology, 10 (3): 175-190.

Huelsenbeck, J. P. and D.M. Hillis (1993). Success of phylogenetic methods in the four-taxon case. Systematic Biology, 42 (3): 247-264.

IUCN (2012). IUCN Red List Categories and Criteria: Version 3.1. Second edition. IUCN, Gland, Switzerland and Cambridge, UK: IUCN: 32pp.

Kumar, S., G. Stecher, M. Li, C. Knyaz and K. Tamura (2018). MEGA X: Molecular Evolutionary Genetics Analysis across computing platforms. Molecular Biology and Evolution, 35 (6): 1547-1549. 
Lawson, R., J.B. Slowinski, B.I. Crother and F.T. Burbrink (2005). Phylogeny of the Colubroidea (Serpentes): new evidence from mitochondrial and nuclear genes. Molecular Phylogenetics and Evolution, 37 (2): 581-601.

Liu, S and D. Rao (2021). A new species of the genus Pareas (Squamata, Pareidae) from Yunnan, China. ZooKeys, 1011: 121.

Rambaut, A., M.A. Suchard, D. Xie and A.J. Drummond (2014). Tracer v1.6 <http://beast.bio.ed.ac.uk/Tracer> Accessed on 16 November 2020.

Rao, D.Q. and D.T. Yang (1992). Phylogenetic systematics of Pareatinae (Serpentes) of Southeastern Asia and adjacent islands with relationship between it and the geology changes [In Chinese]. Acta Zoologica Sinica, 38: 139-150.

Ronquist, F., M. Teslenko, P. van der Mark, D.L. Ayres, A. Darling et al. (2012). MrBayes 3.2: efficient Bayesian phylogenetic inference and model choice across a large model space. Systematic Biology, 61 (3): 539-542.

Shen, Y.Y., X. Chen and R.W. Murphy. (2013). Assessing DNA Barcoding as a Tool for Species Identification and Data Quality Control. PLoS One, 8 (2): e57125.

Silvestro, D. and I. Michalak (2012). raxmlGUI: a graphical front-end for RAxML. Organisms $D i$ versity \& Evolution, 12: 335-337.

Tamura, K., G. Stecher, D. Peterson, A. Filipski and S. Kumar (2013). MEGA6: molecular evolutionary genetics analysis version 6.0. Molecular Biology and Evolution, 30(12): 2725-2729.

Uetz, P. (2020). The Reptile Database <www.reptile-database.org> Accessed on 15 October 2020.

Vogel, G. (2015). A new montane species of the genus Pareas Wagler, 1830 (Squamata: Pareatidae) from northern Myanmar Taprobanica, 7 (1): 1-7.

Vogel, G., T.V. Nguyen, H.T. Lalremsanga, L. Buakzuala, V. Hrima et al. (2020). Taxonomic reassessment of the Pareas margaritophorusmacularius species complex (Squamata, Pareidae). Vertebrate Zoology, 70(4): 547569.

Vogel, G., T.V. Nguyen, Than Zaw, and N.A. Poyarkov (2021). A new species of the Pareas monticola complex (Squamata, Serpentes, Pareidae) from Chin Mountains with additions to the Pareas fauna of Myanmar. Journal of Natural History, 54 (39-40): 2577-2612.

Wang, P., J. Che, Q. Liu, K. Li, J.Q. Jin et al. (2020). A revised taxonomy of Asia snaileating snakes Pareas (Squamata, Pareidae): evidence from morphological comparison and molecular phylogeny. ZooKeys, 939: 45-64.

Yang, J.H., X.Y. Huang, J.F. Ye, S.P. Yang, X.C. Zhang et al. (2019). A report on the herpetofauna of Tengchong Section of Gaoligongshan National Nature Reserve, China. Journal of Threatened Taxa, 11 (11): 14434-14451.

Yang, J.H. and X. Zheng. (2018). A new species of the genus Calamaria (Squamata: Colubridae) from Yunnan Province, China. Copeia, 106 (3): 485-491.

You, C.W., N.A. Poyarkov and S.M. Lin (2015). Diversity of the snail-eating snakes Pareas (Serpentes, Pareatidae) from Taiwan. Zoologica Scripta, 44 (4): 349-361. 